\title{
Effect of bacterial lipase on anaerobic co- digestion of slaughterhouse wastewater and grease in batch condition and continuous fixed-bed reactor
}

\author{
Maha Affes, Fathi Aloui, Fatma Hadrich, Slim Loukil and Sami Sayadi ${ }^{*}$
}

\begin{abstract}
Background: This study aimed to investigate the effects of bacterial lipase on biogas production of anaerobic codigestion of slaughterhouse wastewater (SHWW) and hydrolyzed grease (HG). A neutrophilic Staphylococcus xylosus strain exhibiting lipolytic activity was used to perform microbial hydrolysis pretreatment of poultry slaughterhouse lipid rich waste.
\end{abstract}

Results: Optimum proportion of hydrolyzed grease was evaluated by determining biochemical methane potential. A high biogas production was observed in batch containing a mixture of slaughterhouse composed of 75\% SHWW and $25 \%$ hydrolyzed grease leading to a biogas yield of $0.6 \mathrm{~L} / \mathrm{g}$ COD introduced.

Fixed bed reactor (FBR) results confirmed that the proportion of $25 \%$ of hydrolyzed grease gives the optimum condition for the digester performance. Biogas production was significantly high until an organic loading rate (OLR) of $2 \mathrm{~g} \mathrm{COD/L.} \mathrm{d}$.

Conclusion: This study indicates that the use of biological pre-treatment and FBR for the co-digestion of SHWW and hydrolyzed grease is feasible and effective.

Keywords: Pre-treatment, Slaughterhouse wastewater, Hydrolyzed grease, Anaerobic co-digestion, Fixed bed reactor, Biogas yield

\section{Background}

The slaughtering industry has become a major component of the agro-food sector in Tunisia. Poultry slaughterhouse wastes are considered as ideal substrates for biogas production, because they usually contain a high concentration of organic contaminants and are rich in proteins and lipids [1]. Therefore, their high biodegradability makes them a good candidate for anaerobic digestion (AD) with the concomitant benefit of energy recovery and waste reduction [2].

Lipids represent an important fraction of particulate organic charge in slaughterhouse wastewater and solid

\footnotetext{
*Correspondence: sami.sayadi@cbs.rnrt.tn

Environmental Bioprocesses Laboratory, LMI Cosys-Med, Centre of

Biotechnology of Sfax, BP 1177, 3018 Sfax, Tunisia
}

waste that present low biodegradability. Moreover, a high concentrationof lipids in Slaughterhouse wastes may lead to foam formation and sludge flotation in anaerobic digesters as the lipids are adsorbed onto biomass [3]. Also, it may include a reduction in cell-aqueous phase transfer rates and sedimentation hindrance due to the development of filamentous microorganisms [4].

The application of a pretreatment system to hydrolyze and dissolve fats may improve the biological degradation of fatty wastes, accelerate the process and reduce residence time.

A large number of pre-treatment technologies have been suggested to overcome these limitations, such as mechanical, ultrasonic, thermal and alkaline processing. Most of these processes have been reported to improve the efficiency of $\mathrm{AD}$ in terms of sludge solubilization 
followed by improved biogas production [5]. A further promising alternative is the use of the lipase pretreatment that respects stringent environmental regulations and copes with clean and sustainable application of enzymes [6].

Lipases are enzymes that catalyze the hydrolysis of triacylglycerol to glycerol and long-chain fatty acids (LCFA) at the water-lipid interface [7]. These enzymes showed potential applications in hydrolyzing oil and fats in slaughterhouse wastewaters [8].

Several hydrolysis products were tested and Pancreatic Lipase PL-250 proved to be the most efficient in reducing pork fat particle size and increasing LCFA concentration [9].

The use of lipases seems to be the best alternative for treating lipid-rich wastewaters including those from the poultry industry. Dors et al. [10] showed that chemical oxygen demand (COD) removal of wastewater supplemented with different enzymes concentrations was found to be threefold higher than crude wastewater and the production of methane varied from $569 \pm 95$ to $1101 \pm 10 \mathrm{~mL}$ per gram of COD for crude and pretreated wastewater, respectively. Due to low hydrolysis rate and inhibition effects, sole degradation of lipid substrate through anaerobic treatment is often not an interest. Thus, a combination of high lipid substrate with other substrates commonly known as co-digestion is a subject of interest. Anaerobic co-digestion has been considered as an effective, low-cost, and commercially flexible approach to improve balance of macro and micronutrients, dilution of inhibitory and toxic substances, increased digestion and stabilization rates, and often an increased OLR $[3,11]$.

For a high biodegradability, grease waste is considered as a good substrate to be co-digested with low biodegradability substrates [12].

Indeed, Co-digestion of fat, oil and Grease (FOG) with municipal bio-solids at a rate of $10-30 \%$ FOG by volume of total digester feed caused a $30-80 \%$ increase in digester gas production in two full-scale wastewater biosolids anaerobic digesters [13].

Similarly, Silvestre et al. [14] co-digested sewage sludge with a trapped grease waste. This study resulted in an increase of biogas production by $138 \%$, and suggested that sludge could become acclimatized to higher FOG loads over time, and that this could be an effective approach for improving fat degradation and reducing the inhibitory effects of LCFA.

Li et al. [15] compared the production of biogas from digestion of Waste Activated Sludge (WAS) with WAS co-digested with FOG using Biochemical Methane Potential (BMP) tests. The biogas production associated to the addition of FOG scored an increase of more than $350 \%$.
The objective of this research was to evaluate the effect of lipase pre-treatment on anaerobic co-digestion of SHWW and grease in batch condition and FBR. A novel Staphylococcus xylosus strain was selected for a biological pre-treatment by production of neutrophilic lipase, which could degrade fat and grease present in the lipid waste of poultry industry prior to the anaerobic biological treatment stage.

A Slaughterhouse wastewater was chosen as the liquid substrate because this experiment was part of a larger study evaluating effects of pretreatments on anaerobic co-digestion using a mixture of SHWW and different concentrations of hydrolyzed grease. This study was tested on lab-scale using a FBR with a $3 \mathrm{~L}$ capacity and was designed to study the influence of OLR, on the development of fixed-bed reactor technology for wastewater treatment.

\section{Methods}

\section{Characteristics of the substrates}

The wastewater was taken from the Chahia Company, a local poultry processing plant (Sidi Salem, Sfax- Tunisia) and stored at $4{ }^{\circ} \mathrm{C}$ until use. The utilized effluents represented a neutral solution ( $\mathrm{pH}=7)$, mainly composed of water and organic matter including lipid, phosphorus, nitrogen. The effluent was performed during this study with an average $\mathrm{pH}$ of $6.51 \pm 0.07$, Chemical Oxygen Demand $(C O D)=2800 \pm 537 \mathrm{mg} / \mathrm{l}$, Biochemical Oxygen Demand $\left(\mathrm{BOD}_{5}\right)=1500 \pm 137 \mathrm{mg} / \mathrm{l}$, Total Nitrogen Kjeldahl $(\mathrm{TKN})=290 \pm 40 \mathrm{mg} / \mathrm{l}$, Total phosphorus $(\mathrm{TP})=59 \pm 25 \mathrm{mg} / \mathrm{l}$, Lipid content $=500 \pm 230 \mathrm{mg} / \mathrm{l}$, and Total Suspended Solids (TSS) $=1565 \pm 374 \mathrm{mg} / \mathrm{l}$.

Fatty solid waste samples were collected at the Chahia poultry slaughterhouse waste and stored at $4{ }^{\circ} \mathrm{C}$ until use. The anaerobic sludge used as inoculum in biodegradability tests was collected from the sewage plant of Chotrana located in Tunis- Tunisia.

\section{Microorganism identification, media and culture conditions}

The identification of the bacterial strains has been previously determined according to Bouaziz et al. [16]. The strain was kept in LB medium, refrigerated at $4{ }^{\circ} \mathrm{C}$ and replicated every 3 months. Staphylococcus xylosus was grown overnight at $37{ }^{\circ} \mathrm{C}$ and $200 \mathrm{rpm}$ in a liquid medium autoclaved at $121{ }^{\circ} \mathrm{C}$ for $2 \mathrm{~h}$ containing per liter: $10 \mathrm{~g}$ peptone, $5 \mathrm{~g}$ yeast extract, $5 \mathrm{~g} \mathrm{NaCl}, 1 \%$ olive oil; pH 7.0. A 24 h culture of Staphylococus xylosus was used as inoculum for lipase production.

\section{Lipolytic activity assay}

The lipase activity in the liquid culture was assayed by measuring the free fatty acids released from mechanically stirred emulsions of triacylglycerols, using $0.1 \mathrm{~N}$ 
$\mathrm{NaOH}$ with a $\mathrm{pH}$-Stat (Mertrohm, switzerland). The kinetic assay was performed, in optimal conditions (pH 7.0-7.5 and $37^{\circ} \mathrm{C}$ ) using olive oil emulsion obtained by mixing ( $3 * 30 \mathrm{~s}$ in a Warring blender), $10 \mathrm{~mL}$ of olive oil (Sfax-huile, Tunisia) in $90 \mathrm{~mL}$ of $10 \%$ Gum Arabic (GA). One lipase unit corresponds to $1 \mu \mathrm{mol}$ of fatty acid released per minute [17].

\section{Fat hydrolysis using the lipase producing bacteria Staphylococcus xylosus}

Hydrolysis of neutral fat of slaughterhouse was tested overnight by the use of Staphylococcus xylosus. Cultures used as inocula were performed in Erlenmeyer and incubated in optimal conditions of bacteria strain at $37{ }^{\circ} \mathrm{C}$, $\mathrm{pH}$ 7. They were mixed with stirring rod at a rotation speed of $200 \mathrm{rpm}$ over 5 to 8 days. The hydrolysis degree was verified by calculating Soluble COD (SCOD) and lipid contents.

\section{Lipid extraction and separation}

The extraction of grease was determined through solvent extraction with n-hexane. After removal of the solvent by distillation, the sample was dried and weighed and the fat content determined. To separate neutral lipid classes, 1 to $50 \mu \mathrm{l}$ of neutral lipid extracts or lipid standards at known concentrations were first spotted as 5$\mathrm{mm}$ bands on to a thin-layer silica plate. The elution of lipids was then performed in one step with a hexane/diethyl ether/glacial acetic acid and methanol (78/17/3/2, $v / \mathrm{v} / \mathrm{v} / \mathrm{v})$ solvent mixture, with olive oil and triolein as standards [18]. Following chromatography, the plates were dried at room temperature for $10 \mathrm{~min}$ and then immediately sprayed with an iodine indicator. The plates were then placed in an oven to ensure heating at $100{ }^{\circ} \mathrm{C}$ for $10 \mathrm{~min}$.

\section{Biodegradability assay tests}

Anaerobic biodegradability batch assays were performed in closed glass flasks with a total volume of $500 \mathrm{~mL}$. It was operated at $37{ }^{\circ} \mathrm{C}$ and shaken continuously. Gas volume was measured by syringe-piston displacement. Acclimated anaerobic sludge was transferred to the flasks containing SHWW mixed with different percentages of pretreated grease $(25 \%, 50 \%, 75 \%$, and 100\%) from slaughterhouse poultry waste. Each bottle was fed with an appropriate amount of a substrate and inocula, keeping a VS ratio (VS substrate to VS inocula) at 1:1 in all setups. The tests were carried out in duplicate under batch mode for a period of 50 days. After adjusting $\mathrm{pH}$ to 7.2, all the bottles were flushed with a gas mixture of $75 \% \mathrm{~N}_{2}$ and $25 \% \mathrm{CO}_{2}$ for $3-4$ min to supply anaerobic conditions; the temperature was maintained at $37{ }^{\circ} \mathrm{C}$. Control assays were conducted on the inocula, to estimate the volume of biogas and the biodegradability resulting from the fermentation of the organic solids contained in the anaerobic sludge.

The mean values of net biogas production and biogas yields were calculated at the end of each test. The cumulative biogas yield was expressed in terms of $\mathrm{mL}$ biogas per gram of COD introduced for different conditions.

\section{Reactor experiments}

The co-digestion experiments were performed in a continuously anaerobic fixed bed reactor with a total capacity of $3.5 \mathrm{~L}$ and an active volume of $3 \mathrm{~L}$ (Fig. 1). A Polyurethane foam cube with a specific surface of $200 \mathrm{~m}^{2} / \mathrm{m}^{3}$ was installed in the middle of the reactor as random supporting material. Effluent was continuously loaded into the FBR by using a cycle pump. Biogas volume was monitored daily via the displacement method with water and the corresponding biogas volume was calculated. The biogas was allowed to displace the liquid and the volume of biogas produced was measured either directly by graduation or by the measurement of the weight of liquid displaced [19].

The feed was provided into reactor daily at a fixed time. It was prepared by combining SHWW and HG at a volumetric ratio of $75 \%$ and $25 \%$ respectively at different OLRs.

COD, TSS, fat content, and $\mathrm{pH}$ in the effluent, as well as biogas production were analyzed daily before addition of fresh substrate. At the start-up, the reactor was filled with inoculum for a month to provide a suitable acclimatization of anaerobic biomass prior to the experiments. The general guideline adopted was to increase the OLR when COD removal efficiency and biogas production $( \pm 5 \%)$ were constant at high yields for more than three consecutive days.

Before each new feed addition, the same amount of digested effluent was withdrawn from the top of reactor. This operation was conducted in order to prevent

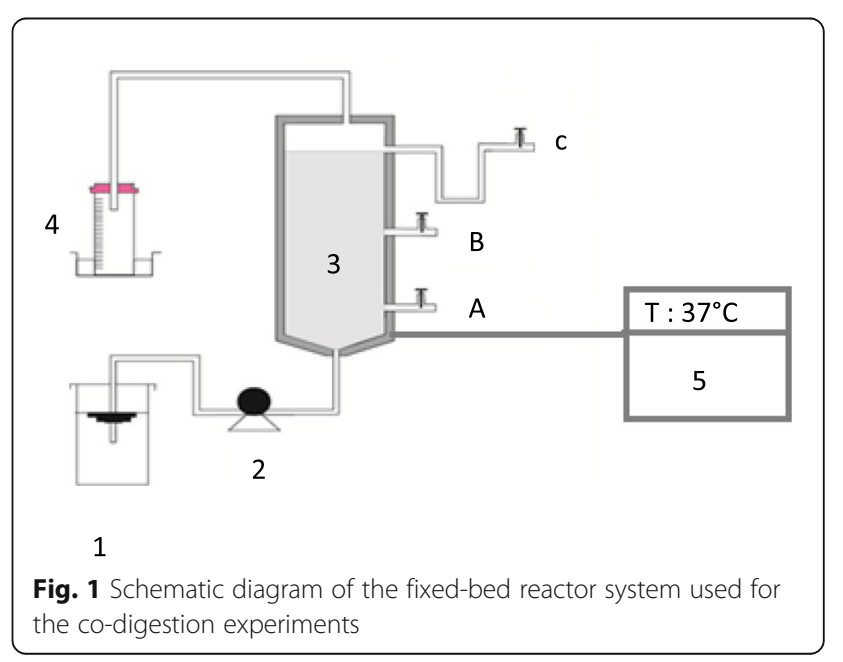


washout of biomass from the anaerobic digester especially during treatment at high OLR.

\section{Analytical methods}

The characterization of the influent and effluent stream of the reactor included the determination of the following parameters: $\mathrm{pH}$, Total chemical oxygen demand (Total COD), Biological oxygen demand $\left(\mathrm{BOD}_{5}\right)$ and Total suspended solids (TSS). The $\mathrm{pH}$ was measured using a pH meter (OHAUS ST-2100). Total and soluble COD were measured spectrophotometrically after a total digestion with $\mathrm{H}_{2} \mathrm{SO}_{4}$ and potassium dichromate at $148{ }^{\circ} \mathrm{C}$ for $2 \mathrm{~h}[20]$. $\mathrm{BOD}_{5}$ was determined by the manometric method with a respirometer [BSB-Controller Model $620 \mathrm{~T}$ (WTW)]. TSS was determined by weighing samples before and after drying overnight at $105{ }^{\circ} \mathrm{C}$. Fat contents were determined according to the standard methods [20].

\section{Results and discussion}

Microbial pre-hydrolysis of fats and greases

Bioremediation of lipid-rich wastes by selected lipase producing bacteria was carried out in wastes emanating from slaughterhouse activities. Microbial lipases are metabolically versatile and hence have advantages in diverse industrial processes [21]. The use of enzymes to enhance hydrolysis of macromolecules and enhance the $\mathrm{AD}$ process has been investigated for many years especially for fats pre-treatment [2]. In the present study, the biodegradation of $5 \%$ of neutral fats from poultry wastes was investigated by using the liquid culture of the lipase producing Staphylococcus xylosus.

Figure (2) illustrates the increasing SCOD and lipid contents obtained during the hydrolysis of poultry waste at different incubations times. In fact, the incubation of grease mixed with LB medium and inoculated with $10 \%$ of bacterial culture (with an activity of 15 units $/ \mathrm{ml}$ ) showed that the optimal period for neutral fat hydrolysis is 6 days (Fig. 2).The hydrolysis is influenced by incubation time, and is evaluated by their ability to increase SCOD. In fact, SCOD value increased while the lipid content was reduced from $17 \mathrm{~g} / \mathrm{l}$ to $1.12 \mathrm{~g} / \mathrm{l}$ after 6 days of culture.

Similar results were reported for slaughterhouse wastewater samples containing between 2.5 and $3 \mathrm{~g} / \mathrm{l}$ of lipids pretreated with pancreatic lipase PL-250 for $4 \mathrm{~h}$ at room temperature [8]. According to these authors, the proposed pretreatment reduced the average particle size to $60 \%$ and increased the free long-chain fatty acid concentrations, indicating partial solubilization of pork fat particles in the slaughterhouse wastewater.

Prasad et al. [21] showed good lipid degradation in slaughterhouse wastewater using S. aureus from $25 \mathrm{~g} / \mathrm{L}$ to $0.320 \mathrm{~g} / \mathrm{L}$ and a reduction of $\mathrm{BOD}_{5}$ from $3.2 \mathrm{~g} / \mathrm{L}$ to $0.011 \mathrm{~g} / \mathrm{l}$ after 12 days of bioremediation.

\section{TLC analysis after grease hydrolysis by the liquid culture of Staphylococcus xylosus}

To confirm the hydrolysis of grease by the liquid culture of Staphylococcus xylosus, samples $(1 \mathrm{ml})$ of the reaction medium were collected at different times of hydrolysis, and lipids were extracted and separated by TLC. Figure 3 shows the lipolysis products of grease when this substrate is hydrolyzed by the produced lipase enzyme in the culture of Staphylococcus xylosus. The grease is constituted essentially by a mixture of TG (triglyceride), FFA (free fatty acid), DG (diglyceride) and MG (monoglyceride). After 4 days of hydrolysis by staphylococcus xylosus culture, we showed the presence of free fatty acid with diglyceride and MG at low intensity. Moreover, spot signals on TLC plate showed clearly that the grease was totally hydrolyzed, and converted into MG and FFA after 6 days of incubation.

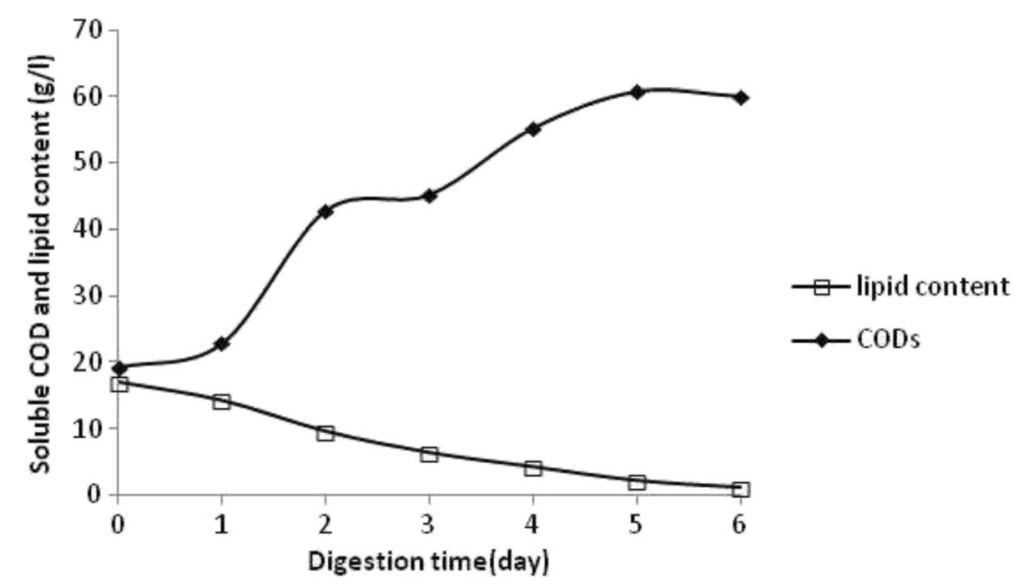

Fig. 2 Evolution of the SCOD and the lipid content during time using pre-hydrolyzed grease wastes 


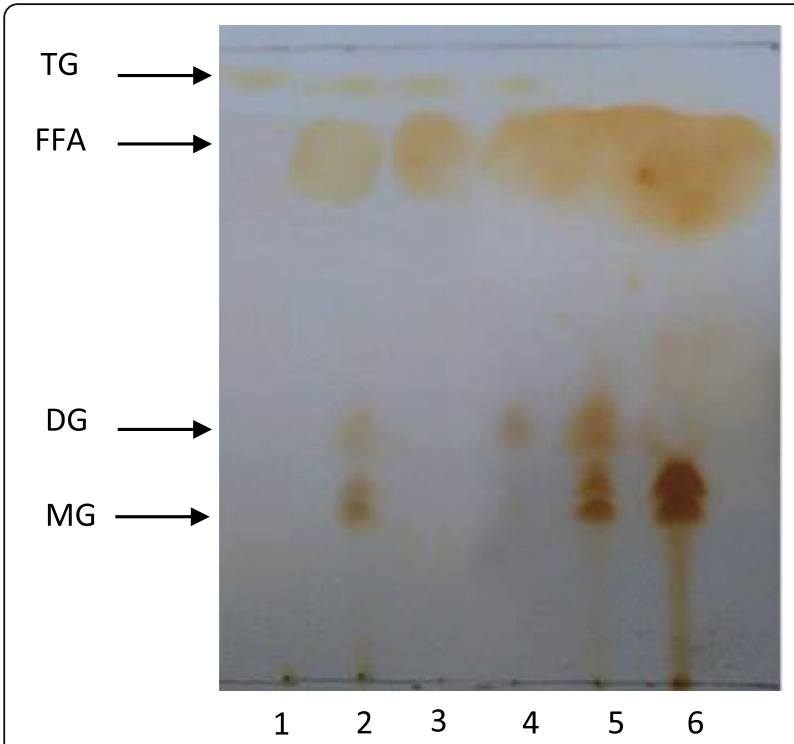

Fig. 3 TLC analysis of grease hydrolysis during time by pure culture of staphylococcus xylosus. Lane 1: Position of triolein; Lane 2: Olive oil; Lane 3: grease after 1 day of incubation; Lane 4: grease after 2 days of incubation; Lane 5: grease after 4 days of incubation; Lane 6: grease after 6 days of incubation

\section{Effect of the concentration of hydrolyzed grease on the} biogas production rate

The cumulative biogas production and kinetic profiles obtained in batch reactors fed with a mixture of untreated slaughterhouse wastewater and different percentages of hydrolyzed grease $(10,25,50,75$, and $100 \%)$ in the presence of the same inoculum are shown in Fig. 4.The biogas production processes ran for about 50 days until biogas production was exhausted. A batch control was also monitored as a serum containing only the inoculum.

The maximum cumulative biogas production from raw SHWW (100\% SHWW) and raw HG (100\% HG) were $940 \mathrm{~mL}$ and $600 \mathrm{~mL}$, respectively giving biogas yields of 0.35 and $0.2 \mathrm{~L} / \mathrm{g}$ COD introduced respectively.

The biogas yield obtained with $100 \%$ hydrolyzed fat is the lowest case after the control (acclimated anaerobic sludge).The inhibition of the anaerobic digestion process was probably due to the accumulation stage of LCFAs, which are important inhibitors on the anaerobic microorganisms, especially methanogens, since the LCFAs adsorption onto the methanogen cells may cause damages to the cell membrane and inhibit the transport of nutrients phenomena through the cell wall $[22,23]$. Multiple studies have suggested maximum concentrations of LCFAs, above which anaerobic digesters are likely to experience excessive methanogen inhibition $[6,13]$.

The cumulative biogas production at the end of fermentation in serum bottles were 1200, 2560, 2120,and $1810 \mathrm{~mL}$ corresponding to the proportions $10 \%, 25 \%$, $50 \%$ and $75 \%(\mathrm{v} / \mathrm{v})$ of hydrolyzed fats, respectively. High biogas production was observed in the batch containing a mixture of slaughterhouse wastewater consisting of $75 \%$ SHWW and 25\% hydrolyzed grease with a biogas yield of $0.6 \mathrm{~L} / \mathrm{g}$ COD introduced, this production was twice higher than the crude slaughterhouse wastewater (100\% SHWW) (Fig. 5). Similar results were described for the hydrolysis of lipids present in slaughterhouse wastewater using a commercial lipase from Candida rugosa. These results show that the pretreated wastewater generated about five times more biogas $(500 \mathrm{~mL})$ than the crude wastewater $(107 \mathrm{~mL})$ [24].

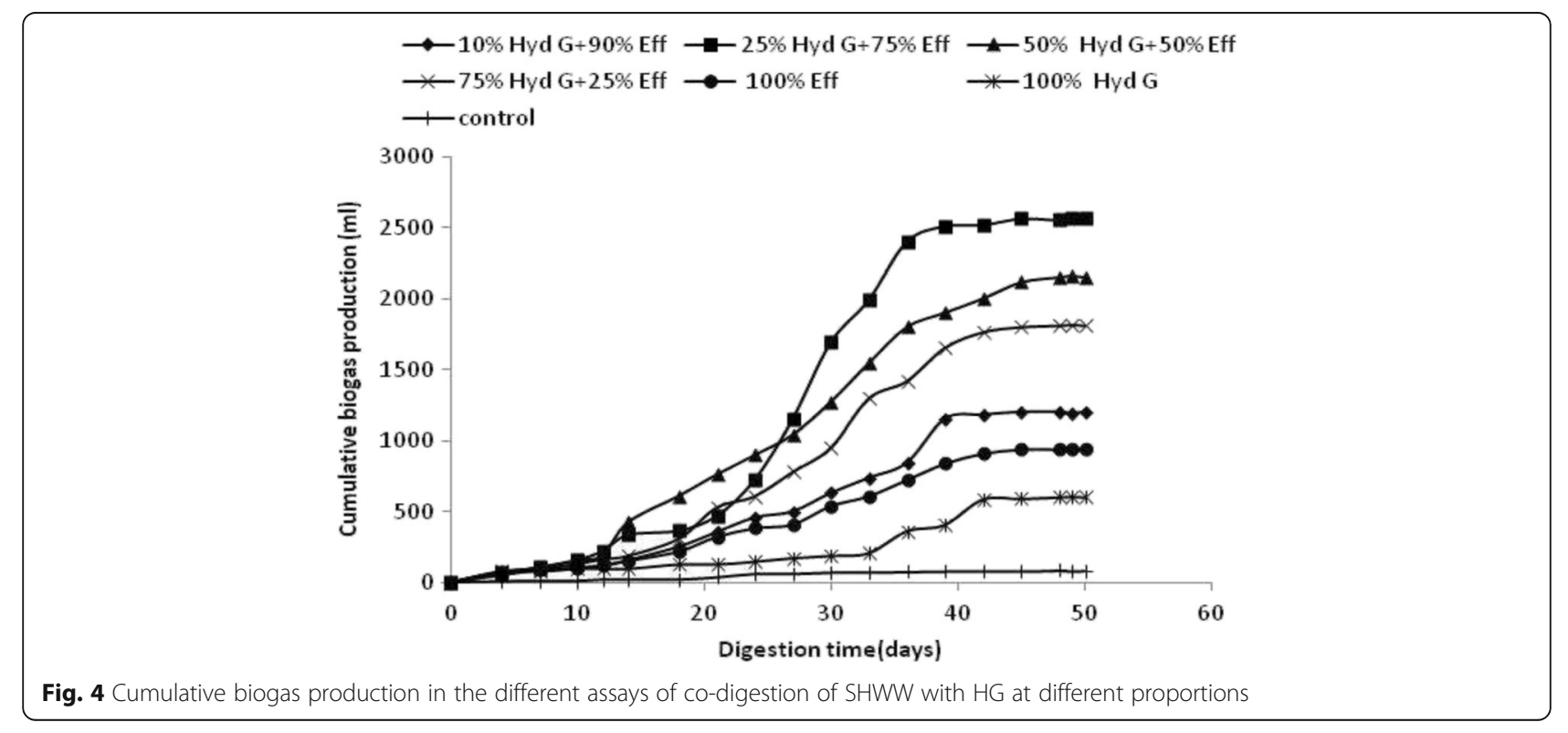




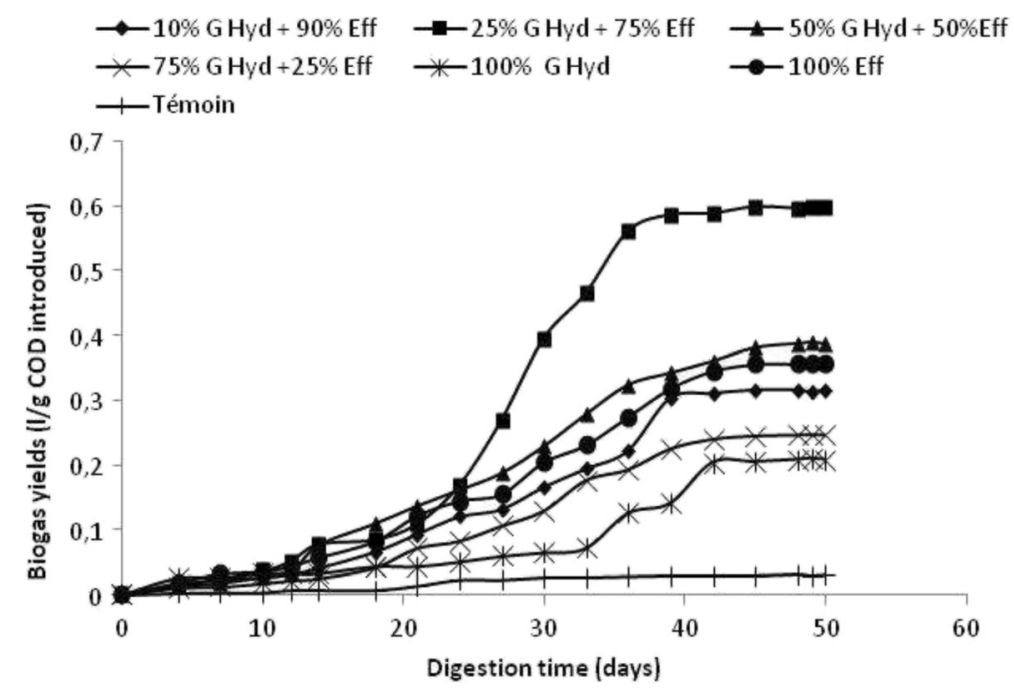

Fig. 5 Evolution of biogas yields in the different assays of co-digestion of SHWW with HG at different proportions

As for the removal of organic matter in terms of COD, more than $50 \%$ were obtained in all cases, with a maximum value reached of $72 \%$ for $25 \%$ of hydrolyzed fats.

The COD removal was effective owing to the lipid bioconversion into their products (glycerol and LCFA). Mendes et al. [6] showed that the lipid fraction removal by the pancreatic lipase improved organic matter reduction and the biogas formation since pretreated samples were not subjected to sludge flotation, whereas this phenomenon was observed for untreated wastewater.

\section{Reactor operation}

The fixed bed reactor was fed with $25 \%$ of hydrolyzed fat and $75 \%$ of industrial effluent for 2 months at $37{ }^{\circ} \mathrm{C}$ in order to confirm the most efficient mixing ratio and to investigate the performance of the reactor under different OLR.
The start-up period of FBR was relatively about 30 days, noted by an increase of methanogenic Archaea activity as measured by COD degradation and biogas production.

The evolutions of OLR and biogas yields, during the anaerobic treatment are presented in Fig. 6.

After the start-up period of the digester, low OLR was maintained (1.3-1.5 g COD/L .d). It should be noted that during this period, acidogenic bacteria use compounds that can be easily metabolized, such as sugars and carbohydrates, whereas methanogens that have a slower metabolism are hindered by the presence of intermediates known as long chain fatty acid (LCFAs). It is reported that LCFAs inhibit metabolism and become the main cause of process instability [25-27].

A maximum biogas yield of $0.4 \mathrm{~L} / \mathrm{g}$ of introduced COD was registered. An increase of biogas yield was observed after the increase of OLR from 1.5 to $2 \mathrm{~g} \mathrm{COD/}$

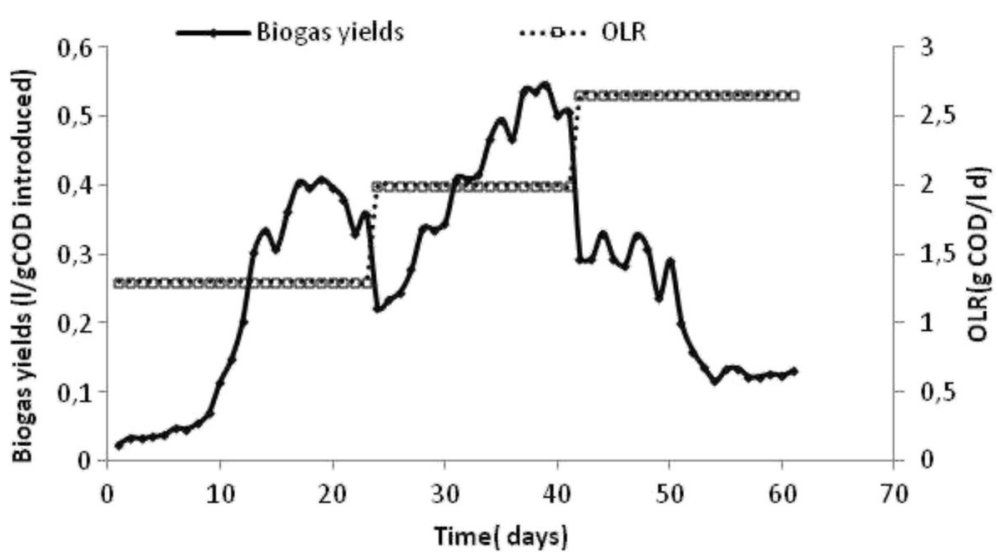

Fig. 6 Evolution of organic loading rate and biogas yields during anaerobic co-digestion of SHWW and HG in FBR 


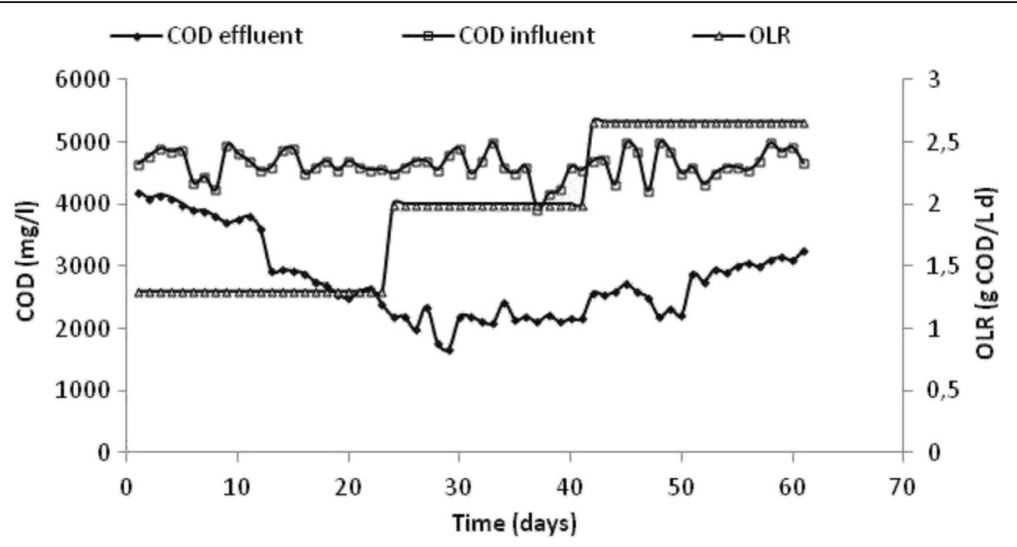

Fig. 7 Evolution of the COD inlet and outlet of the reactor and OLR during the anaerobic co-digestion of SHWW and HG in FBR

L.d and during the period between 25 and 40 days reaching a yield of $0.6 \mathrm{~L} / \mathrm{g}$ introduced COD.

By increasing the OLR from 2 to $2.5 \mathrm{~g}$ COD/L.d, a decrease in the biogas production was observed. In addition, a low biogas yield $(0.3 \mathrm{~L}$ biogas/g introduced COD) was registered at HRT of 1.5 day. This decrease can be explained by the effect of the high LCFA concentrations on the anaerobic microorganisms [28].

Results of influent and effluent COD obtained during the period of continuous operation of the fixed bed reactor are shown in Fig. 7.

The variation of influent COD seems to be constant between 4 and $5 \mathrm{~g} / \mathrm{L}$. The performance of the fixed bed reactor was affected by the increase of OLR. Therefore, the average of COD removal efficiencies increased from 30 to $53 \%$ for OLR of 1.3 and $2 \mathrm{~g} \mathrm{COD/L.d} \mathrm{respectively.}$ For OLR of $2.5 \mathrm{~g}$ COD/L.d, the co-digestion process was disturbed. This perturbation in the bioreactor can be explained by the increase of lipid amount in influent [28] which caused an inhibition in growth bacteria.

Consequently, the addition of fats not only allowed higher gas production but also increased the stability of the digestion process. Martinez et al. [29] suggested that the addition of the co-substrate improved the digestion stability and biogas yield via an increase in the OLR from 0.29 to $0.65 \mathrm{gVS} \mathrm{L}^{-1} \mathrm{~d}^{-1}$ for the mesophilic system. In the studies realized by Luostarinen et al.[12], the codigestion of grease trap sludge from a meat-processing plant and sewage sludge increased specific methane production in reactor experiments (maximum $463 \mathrm{~m}^{3} / \mathrm{tVS}$ added) compared to digestion of sewage sludge alone $\left(278 \mathrm{~m}^{3} / \mathrm{tVS}\right.$ added).

\section{Conclusion}

The co-digestion of hydrolyzed grease and slaughterhouse wastewater was successfully performed in batch and reactor conditions. The best biogas yield and biodegradability were obtained at $25 \%(v / v)$ of HG. This proportion was tested in semi-continuous operation. Results confirmed that co-digestion of $75 \%$ SHWW with 25\% HG (v/v) in anaerobic FBR yields the best biogas yields and process stability until an OLR of $2 \mathrm{~g}$ COD/L .d, by acquiring a stable environment, nutritional balance in the anaerobic micro-ecosystem and reducing inhibitory effect of LCFAs by the application of microbial pretreatment during hydrolysis. This is due to the increase in the transportation rate of soluble substrate into biomass to induce biogas conversion.

\section{Abbreviations}

AD: Anaerobic Digestion; COD: Chemical Oxygen Demand; HG: Hydrolyzed grease; HRT: Hydraulic retention time; LCFA: Long-chain fatty acids; OLR: Organic loading rates; SCOD: Soluble Chemical Oxygen Demand; SHWW: Slaughterhouse wastewater

\section{Acknowledgements}

Financial support was provided by the Tunisian Ministry of Higher Education and Scientific Research under "the Contracts in the framework of a MOBIDOC Ph.D. thesis financed by the EU within a PASRI framework". The authors are also grateful to the Chahia Company-Sfax for their help and access to their wastewater treatment plant. The authors are equally grateful to Kamel MAALOUL, English professor and translator, for having proofread the manuscript.

\section{Availability of data and materials}

All data generated or analyzed during the current study are available from the corresponding author on reasonable request.

\section{Authors' contributions}

MA, FA, FH and SL designed the experiments, analyzed the data and drafted the manuscript. SS conceived research and approaches and gave final approval of the manuscript to be published. All authors read and approved the final manuscript.

\section{Funding}

The funders had no role in the design of the study and collection, analysis, and interpretation of data and in writing the manuscript.

Ethics approval and consent to participate Not applicable.

Consent for publication

Not applicable. 


\section{Competing interests}

The authors declare that there are no competing interests.

\section{Publisher's Note}

Springer Nature remains neutral with regard to jurisdictional claims in published maps and institutional affiliations.

Received: 31 May 2017 Accepted: 2 October 2017

Published online: 10 October 2017

\section{References}

1. Jensen PD, Mehta CM, Carney C, Bastone DJ. Recovery of energy and nutrient resources from cattle paunch waste using temperature phased anaerobic digestion. Waste Management. 2016;51:72-80.

2. Harris PW, McCabe BK. Review of pre-treatments used in anaerobic digestion and their potential application in high-fat cattle slaughterhouse wastewater. Appl Energy. 2015;155:560-75

3. Borowski S, Kubacki P. Co-digestion of pig slaughterhouse waste with sewage sludge. Waste Management. 2015;40:119-26.

4. Valladao ABG, Freire DMG. Magali christe Cammarota M C: Enzymatic prehydrolysis applied to the anaerobic treatment of effluents from poultry slaughterhouses. Int Biodeterior Biodegrad. 2007;60:219-25.

5. Abudi ZA, Hu Z, Sun N, Xiao B, Rajaa N, Liu C, Guo D. Batch anaerobic codigestion of OFMSW (organic fraction of municipal solid waste), TWAS (thickened waste activated sludge) and RS (rice straw): Influence of TWAS Dand RS pretreatment and mixing ratio. Energy. 2016;107:131-40.

6. Mendes AA, Ernandes B. Pereira, Castro HF: Effect of the enzymatic hydrolysis pretreatment of lipids- rich waste water on the anaerobic biodigestion. Biochem Eng J. 2006;32:185-90.

7. Mendes AA, Oliveira PC, Castro HF. Properties and biotechnological applications of porcine pancreatic lipase. J Mol Catal B Enzym. 2012;78:119-34.

8. Masse L, Kennedy KJ, Chou S. Testing of alkaline and enzymatic hydrolysis pretreatments for fat particles in slaughterhouse wastewater. Bioresour Technol. 2001:77:145-55.

9. Masse L, Massé DI, Kennedy KJ. Effect of hydrolysis pretreatment on fat degradation during anaerobic digestion of slaughterhouse wastewater. Process Biochem. 2003;38:1365-72.

10. Dors G, Mendes AA, Pereira EB, Castro HF. Furigo JrA: Simultaneous enzymatic hydrolysis and anaerobic biodegradation of lipid-rich wastewater from poultry industry. Appl Water Sci. 2013;3:343-9.

11. Alqaralleh R, Kennedy $K$, Delatolla R, Sartaj M. Thermophilic and hyperthermophilic co-digestion of waste activated sludge and fat, oil and grease: Evaluating and modeling methane production. J Environ Manag. 2016;183:551-61.

12. Luostarinen S, Luste S, Sillanpaa M. Increased biogas production at wastewater treatment plants through co-digestion of sewage sludge with grease trap sludge from a meat processing plant. BioresourTechnol. 2009: 100:79-85.

13. Hunter Long J, Aziz TN, Francis L, los Reyes d III, Ducoste J JJ. Anaerobic codigestion of fat, oil, and grease (FOG): A review of gas production and process limitations. Process Saf Environ Prot. 2012;90:231-45.

14. Silvestre G, Rodriguez-Abalde A, Fernandez B, Flotats X, Bonmati A. Biomass adaptation over anaerobic co-digestion of sewage sludge and trapped grease waste. Bioresour Technol. 2011;102:6830-6.

15. Li C, Champagne P, Anderson BC. Enhanced biogas production from anaerobic co- digestion of municipal wastewater treatment sludge and fat, oil and grease (FOG) by a modified two-stage thermophilic digester system with selected thermo-chemical pre-treatment. Renew Energy. 2015:83:474-82.

16. Bouaziz A, Horchani H, Ben Salem N, Gargouri Y, Sayari A. Expression, purification of a novel alkaline Staphylococcus xylosus lipase acting at high temperature. Biochem Eng J. 2011;54:93-102.

17. Cherif S, Mnif S, Hadrich F, Abdelkefi S. Sayadi S:Strategy for improving extracellular lipolytic activities by a novel thermotolerant Staphlococcus sp. strain. Lipids in Helth and Disease. 2011;10:209-16.

18. Ghamgui H, Miled N, Rebai A, Chaabouni MK, Gargouri Y. Production of mono-olein by immobilized Staphylococcus simulans lipase in a solventfree system: Optimization by response surface methodology. Enzym Microb Technol. 2006;39:717-23.

19. Valke $D$, Verstraete $W$. A practical method to estimate the acetoclastic methanogenic biomass in anaerobic sludges. J Water Poll. 1983;55:1191-5.
20. APHA. Standard Methods for the Examination of Water and Wastewater. 22th ed. Washington DC, USA: American Public Health Association; 2012.

21. PrasadM P, Manjunath K. Comparative Study on biodgradation of lipid-rich wastewater using lipase producing bacterial species. Indian J Biotechnol. 2011;10:121-4

22. Martínez EJ, Fierro J, Sánchez ME, Gómez X. Anaerobic co-digestion of FOG and sewage sludge: study of the process by Fourier transforms infrared spectroscopy. Int Biodeterior Biodegrad. 2012;75:1-6.

23. Noutsopoulos C, Mamais D, Antoniou K, Avramides C, Oikonomopoulos P. Fountoulakisl:Anaerobic co-digestion of grease sludge and sewage sludge: the effect of organic loading and grease sludge content. Bioresour Technol. 2013;131:452-9.

24. Peireira EB, Furigo A Jr, Castro HF, Reginatto VS. Degradation of fat and grease in slaughterhouse waste water by a commercial microbial lipase. Biol.Technol. 2006:47:405-11.

25. Cirne DG, Paloumet X, Bjornsson L, Alves MM, Mattiasson B. Anaerobic digestion of lipid-rich waste-Effects of lipid concentration. Renew Energy. 2007;32:965-75

26. Chen Y, Cheng JJ, Creamer KS. Inhibition of anaerobic digestion process: A review. BioresourTechnol. 2008:99:4044-64.

27. Hanaki K, O'Nagase M, Matsuo T. Mechanismofinhibiton causedbylong chain fatty acids in anaerobic digestion process. Biotechnol Bioeng. 1981;23:1591-610.

28. Rasit N, Idris A, Harun R, WAWAK G. Effects of lipid inhibition on biogas production of anaerobic digestion from oily effluents and sludges: An overview. Renewable and Sustainable Energy. 2015;45:351-8.

29. Martínez EJ, Gil MV, Fernandez C, Rosas JG, Gómez X. Anaerobic Codigestion of Sludge: Addition of Butcher's Fat Waste as a Co-substrate for Increasing Biogas Production. PLoS One. 2016;114:e0153139.

\section{Submit your next manuscript to BioMed Central and we will help you at every step:}

- We accept pre-submission inquiries

- Our selector tool helps you to find the most relevant journal

- We provide round the clock customer support

- Convenient online submission

- Thorough peer review

- Inclusion in PubMed and all major indexing services

- Maximum visibility for your research

Submit your manuscript at www.biomedcentral.com/submit
C) Biomed Central 